\title{
Classroom Participation and Development of Student Attitudes: A Study of Active Learning Practices in Ethiopian Primary Education
}

\author{
Teshome Nekatibeb Begna \\ Centre for Comparative Education and Policy Studies, Addis Ababa University, Ethiopia
}

\begin{abstract}
Ethiopian primary education has experienced a shift from traditional instruction to active learning methodologies in the classroom over the last two decades. However, the degree to which these methods are practiced and students are benefited are very far from known. The main purpose of this study was to explore classroom participation and pupils' attitudinal development in actual process of instruction in Ethiopia. The study draws its background from the Young Lives Research on Mathematics Education in Ethiopia. The Young Lives Project used survey research in combination with field observations and questionnaires to obtain information from many teachers and students. Findings indicate that the extent to which students actively participate in classroom instruction is dominated by watching and listening to the teacher. Writing or drawing in exercise books as well as engagement in alternative off task activities are significantly prevalent. Teacher behaviors are in transition in the sense that they have significantly reduced using lectures and one-way explanations. Wastage of time on task and corporal punishment have been significantly reduced. However, they are still far from fully engaging students in their lessons. From these findings, it was concluded that focus should be given to teacher capacity development and the improvement of school environments to advance the use of active learning pedagogies in schools.
\end{abstract}

Keywords: active learning, classroom participation, student attitudes, teacher behaviours

\section{INTRODUCTION}

The concept of learning is not only complex, but also how it takes place is intriguing. For some, learning is any relatively permanent change in behaviour that occurs because of practice and experience (Morgan et al., 1999). For others, learning is the development of new knowledge, skills or attitudes as an individual interacts with information and environment (Heinich et al., 1996). Still for others, it is a process of discovery which my lead to a new understanding of the world and ourselves. Differences of understanding in what constitutes learning and how it takes place are related to the researcher's ontological and epistemological perspectives or assumptions. A researcher may consider knowledge as something that exists independently of the human mind, absolute and given. Conversely, s/he can assume that learning and how it takes place is a product of human consciousness and cognition. In the first case, knowledge is something to be acquired while in the second it is something to be experienced and constructed. Based upon their ontological, epistemological and other assumptions, Burrell and Morgan (1996) categorise social scientists into "objectivist" and "subjectivist" researchers.

Learning has remained a defining human characteristic despite complexities and differences surrounding the concept and how it takes place in practice. Consequently, it has been a subject of research and a distinct field of study in theoretical psychology. Overall, Heinich et al. (1996), summarize theories of learning into behaviourist, cognitivist, constructivist and social-psychological theories. The main concern of behaviourists is how to shape the behaviour of organisms as desirable responses to the environment. Cognitive psychologists, consider learning as the reception, processing and manipulation of information. For constructivists, the essence of learning is the engagement of learners in meaningful experiences. In social psychology, the main concern is with the effects of the social organization of the classroom on learning.

Using the categorization by Burrell and Morgan (1996), it might not be easy to categorize learning theories into "objectivist" or "subjectivist" because there can be an overlap or continuum in their explanations about the nature of learning and how it takes place in human beings. For instance, the 
contributions of cognitive theory of learning is obvious to constructivism as it was the first to elaborate or explain how the human mind is active in processing and storing information. Heinich et al. (1996) even consider constructivist theories of learning as the extensions of cognitive psychology. Similarly, one can not argue from practice that learning does not involve "memorization" or that "reward" does not strengthen the response of the learner to the stimuli presented to him/her in the form of curricula as behaviourists assert.

However, it is possible to argue that constructivist theories are emerging as distinct and dominant approaches to learning today. These theories consider knowledge as a constructed reality and contradict the view that knowledge is given and absolute. Thus, constructivist theories are subjectivist philosophies of science which assume that reflection on experience constitutes the basis of understanding the world. For constructivists, learning is a search for meaning and it must be based on active engagement or interaction that leads to discovery and personal interpretation of experience.

Lev Vygotsky (1978), who is considered as the father of constructivist and active learning theory, was convinced that social interaction plays a fundamental role in the development of cognition. For him, culture determines individual development and what a child learns emanates from social interaction. In this sense, both the content and means of cognition or thinking are acquired from cultural interaction. Thus, learning is essentially social.

There is an overwhelming agreement that researchers and policy makers around the world have endorsed the use of active-learning and student-centered pedagogies over the past several years for a variety of reasons (Darling-Hammond and Bransford, 2005; Hopkins 2002; Prince, 2004). According to Leu and Price-Rom (2006), this model of teaching highlights minimal teacher lecturing or direct transmission of factual knowledge, multiple small group activities that engages students in discovery learning or problem solving, and frequent student questions and discussion. For Bransford et al. (2005) active learning models are organized on more hands-on learning principles, emphasizing higher-order thinking skills leading to better performance in student learning. According to Prince (2004) active learning has attracted strong advocates among faculty in higher education because it presented a radical alternative to traditional instruction.

Regardless of this widespread endorsement by relevant authorities and stakeholders, however, there are many challenges to effectively practice active learning and to determine the extent of its impact after implementation. Challenges to promote and practice active learning include teacher education reform, improving material conditions of schools, the inconsistency between active learning and school assessment as well as cultural appropriateness (see Alexander, 2000). According to Prince (2004) determining the impact of active learning has been difficult because it affects more than one learning outcome. Due to this, obtaining comprehensive data on the outcomes of this type of learning methods has remained illusive and inconclusive. Moreover, in many circumstances it has not simply been possible to measure several relevant outcomes that are targeted by active learning methods.

Ethiopia endorsed the use of active learning methods after the proclamation of its 1994 Education Training Policy. This policy and its associated documents refer to the new methodological innovation as problem-solving method, learner-centred method, child-centred learning, non-traditional methods of instruction etc. For instance, the following was stated in the main Policy Document:

One of the aims of education is to strengthen the individual's and society's problemsolving capacity, ability and culture starting from basic education at all levels (Transitional Government of Ethiopia; 1994:1)

The main problem of the new reform was not only the reference it made to different notions in the semblance of active learning, but also the fact that no mention was made of the practical strategies or activities to be practiced in the classroom by teachers and students. The Ethiopian Education and Training Policy document as well as other implementation guidelines were also quite mute about the expected outcomes from active learning.

In retrospect, it can be argued that the adoption of active learning methods without unity of purpose, clarity of goals and articulated outcomes provided a context whereby the school system danced in the dark without clear vision. The prevalence of this gap was not without its consequences. Foremost, it created significant confusions as to what constitutes active learning and to variations in practicing it in the classroom. Everyone implemented it as it seems appropriate and even sometimes the way it was not intended (Dufera, 2007). In fact, it is difficult to imagine that these confusions were limited only 
to the classroom level. Challenges were very much possible to have emerged in teacher training, curriculum planning, school leadership and provision of learning resources to schools. Sensing these challenges, the Ethiopian government was actively working with international development partners to correct deficiencies over the years. For instance, USAID (2007) has reported that it has been supporting the school sector in pre-service and in-service teacher education, school leadership, materials design and production, and continuous assessment with the central objective of supporting active learning methodologies in Ethiopia. Another and the second scenario was the emergence of "rainbow" research in the investigation of how the new approach is perceived and implemented at the micro-level.

To start with, no credible study could be found on the use of "problem-solving" method as it was originally and directly mentioned in the Education and Training Policy of Ethiopia. However, there were some studies which somehow addressed the problems of active learning using such notions as "innovative learning", "learner-centred methods" etc. (see Duferea, 2007; Melese et al., 2008, Kocsev et al., 2010). While it is very difficult to determine whether these studies were attending to the same subject, it is possible to commonly observe that they were conducted as case studies. Consequently, their scopes were not only limited to their areas of investigation, but also their implications for policy making were insignificant. Perhaps, a different type of study was one which was reported by USAID (2007). It is a longitudinal survey of active learning practices and behaviours in USAID supported schools. While the focus of this study on classroom practices is a welcome development, it shares the common limitations of other research for not including the results or outcomes of those practices in terms of student behaviour or development. Still there are studies under the rubric of active learning which attempted to pre-test the effectiveness of active learning behaviours instead of observing the practice of active learning by students and teachers as the result of the existing policy (see Desta et al., 2010).

This study explores teachers and student practices in the classroom as well as the outcomes of those practices in terms of student attitudinal development. For so doing, it used the Young-Lives project data in cross-sectional perspectives. The Young Lives Project is a part of an international study of childhood poverty following the changing lives of 3,000 children in Ethiopia. The main intent here is to provide a holistic view of participatory activities in the classroom by teachers and students, how those acts relate to the formation of students' attitudes and thereby fill the gaps in understanding of the contributions of using active learning methods in Ethiopian primary schools.

\section{OBJECTIVES AND SCOPE OF THE STUDY}

The main objective of this study is to analyze classroom participation and pupils' attitudinal development in actual process of childhood instruction in Ethiopia. It is an attempt to investigate the extent to which active learning methods are practiced and benefited students in primary schools. The specific objectives are the following:

- To explore and describe teacher activities in terms teacher-oriented whole class activities and child-centred activities taking place in the classroom.

- To analyze student participation in relations to teacher-oriented whole class activities and childcentred activities, gender, location, region and age.

- To explore student attitudes in classes implementing active learning, and examine how teacher and student participation relate to student attitudes.

Studying active learning practices and how these methods relate to student attitudes is significant because it is the first attempt which is meant to provide a comprehensive understanding of the instructional process and its outcomes. So far studies rarely focused on classroom participation and student's performance simultaneously. A holistic approach also provides insights about how active learning practices vary among schools and the conditions that contribute to those variations. By so doing this study supports policy makers to improve the efficiency and effectiveness of schools by indentifying priorities for action. It can also enlighten school level actors including parents, principals, teachers and students on conditions that may be considered in practice to improve the performance of schooling. Although active learning methods are expected to be practiced at levels of the educational system, this study is limited only to primary education. Theoretically these approaches may include several dimensions, but this study focuses on classroom participation or activities and student 
performance. As already elsewhere, the study was derived from the data provided by the Young Lives Project in Ethiopia. This project has already collected data for many purposes, but the focus here is only those variables that have direct relevance to the current report. Considering these scenarios and the scope of the study, the overarching question leading this investigation is framed as follows: What does active classroom participation and student attitudes look like in Ethiopian primary classrooms? Subsequent questions derived from this generic question focus on the following dimensions: What is the extent to which teachers practice whole class teacher-oriented activities and student -centred activities? To what degree students participate in whole class teacher-oriented activities and studentcentred activities? How does student participation in lessons vary among students in terms of gender and location? What are the extent to which students demonstrate positive attitude towards learning? How much do students exposed to active learning methodologies demonstrate self-confidence and positive aspirations for the future?

\section{Frame of AnAlysis}

\subsection{Active Learning an Act of Participation}

Often presented as a shift away from traditional instruction, active learning is receiving a growing attention. For over a long period of time, traditional behavioural approaches focused on the learner as a passive participant rather than as an active participant in the instructional process (Ford and Kraiger, 1995). Traditional behaviourists emphasized the importance of tightly structured learning and provision of a step-by-step instruction in order to control learners and efficiently develop routine expertise and analogous transfer of skills, or the transfer of skills to problems similar to those encountered during learning (Ivancic and Hesketh, 1995).

More recently, however, learner-centred approaches are increasingly evolving with the view that learners must be active participants in their own learning (Farrell,2006). This view differs from all other approaches as it predicates on the empowerment of the learner to control his/her learning and on shaping self-regulatory and creative behaviours of learners during the process of instruction (Bransford, Brown, \& Cocking, 1999). One additional reason for the shift to active learning has to do also with the realization that the routine expertise developed through traditional approaches can be liabilities in the flexible and ever chaining work environments.

Active learning approaches promote inductive learning in which individuals explore and experiment with a task to infer to the rules, principles, and strategies for effective performance (Frese et al., 1991). In contrast, more passive approaches to learning assume that people acquire knowledge by having it transmitted to them by some external source (Schwarz and Bransford, 1998).

Despite the increasing significance given to active learning approaches, it is not possible to give a universally accepted definition to the concept of active learning. According to Prince (2004), however, it is possible to provide some generally accepted definitions and to highlight distinctions in how common terms are used. This general definition takes active learning as any instructional method that engages students in the learning process (Prince, 2004; Silverman, 1996; Farrell, 2006). Prince (2004) elaborates that active learning requires students to do meaningful learning activities and think about what they are doing. In this sense, active learning could include traditional activities such as home work, but in practice it involves activities that are introduced to the classroom. The core elements of active learning are student activity and engagement in the learning process. In agreement with the above views, we argue that active learning is a process of putting learners in cultural contexts and provide them with multiple opportunities to engage in inquiry at many different levels. It is a process involving children's perceptions, related encoding and subsequent retrivel of information leading to modifications in future behaviours and attitudes. In the culture of classroom setting, knowledge is socially constructed and integrated into the life of the learning community and learners are motivated to learn by their desire to participate in this community. Thus, learning becomes an act of participation and failure to learn, in this sense, implies exclusion from participation.

\subsection{Strategies and Practices in Active Learning}

There is a general understanding that active learning approaches involve the systematic influence and support of the cognitive, emotional and motivational development of learners to enhance the learning process in addition to 'learning by doing'. However, it is hardly possible to find a common strategy or model that constitutes what active learning is in practice. One main reason may be the fact that different theories and philosophies of education recognize the significance of learner's active 
participation in the process of learning. As Kolb (1982) indicates, the idea that the learner should be an active participant in the learning process is not unique to active learning approach; it cuts through several philosophies and approaches, such as experiential learning and action learning.

To exhaustively elaborate active learning strategies, Silberman (1996) has presented 101 strategies of active learning to teach any subject. These strategies are structured into five main areas: arrangement of the physical environment, getting students to become active from the start, helping students to acquire knowledge, skills and attitudes actively, and making learning unforgettable. Each of these main strategies was operationalized into main activities and sub-activities.

Referring to evidences in classroom situations, Prince (2004) includes four strategies in active learning: introduction of student activity into traditional lecture/ instruction, promotion of student engagement, collaborative learning, cooperative learning and problem based learning. Introduction of student activity into traditional instruction involves a pose procedure whereby students are given some activity interrupting instruction. Student engagement involves designing activities around important learning outcomes and promotes thoughtful engagement on the part of the student. In collaborative learning the central element is the working together of students' in small groups toward a common goal. Cooperative learning is a form of structured group work where students pursue common goals while being assessed individually. Problem solving learning (PBL) is an instructional method where relevant problems are introduced at the beginning of the instruction cycle and used to provide the context and motivation for learning that follows. It is always active and usually, but not necessarily, collaborative or cooperative and involves significant amount of self-directed learning on the part of students.

Bell and Kozlowiski (2007) also provided a framework of active learning strategies in the context of training programs. Their framework includes exploration, framing, emotion-control and integration. Their focus in exploration is the emphasis on meta-cognitive, exploratory/experimental and ability based learning. In framed learning, they indicate the importance of motivation, achievement and goal orientation of learning as well as the provision of feedback by way of error framing. With reference to emotion control, these authors indicate how reduction of anxiety and management of susceptibility to influence from out side situations are significant in active learning. Bell and Kozlowiski (2007) also note that positive influences using active learning methods are enhanced if distinct strategies and process pathways are summarized and integrated.

In the current study, active learning strategies or practices are conceptualized as teacher-oriented whole class activities, child-centred activities and off-task activities at the child or student level. Teacher - oriented whole class activities refer to the full engagement of the child where the focus is on activities directed by the teacher to the whole class or a large group. The following sub-activities constitute this main element of the construct: listening/watching the teacher, offering to answer questions, chanting in unison, making contribution to the lesson and writing in exercise books.

Child-centered activities refer to the full engagement of children where the focus is on activities that provide them some choice over what they do or can control, how fast or slowly they do it, or on working within a small group of children on a shared activity. The following sub-activities constitute this main element of the construct: individual activity, group activity and conversation with teacher. Off task activities refer to conditions where the child is not active, not concentrating on the lesson or task, day-dreaming or dozing, waiting around or in other ways not engaged. It also includes misbehaving and being disciplined.

At teacher level, active learning strategies were also divided into teacher-oriented whole class activities, child-centred activities and off-task activities. Under teacher-oriented whole class activities, the units of observation were explaining a lesson, lecturing, group call and response, questioning and setting work. Child-centered activities included discussion, guiding group work and the individual student. Other activities set for observation in this category were discipline, administration, marking work, chatting and temporary absence.

\subsection{Active Learning and Student Performance}

A summary of the literature by Bonwell and Eison (1991) indicate that active learning leads to better student attitudes and improvements in students' thinking and writing. It also indicates that some forms of active learning surpass traditional lectures for retention of material, motivating students for further study and developing thinking skills. 
The fact that a variety of instructional methods are labelled as active learning has commonly led to separate assessments of the effectiveness of different learning methods, strategies or practices. Pointing to the effectiveness of introducing student activity into traditional instruction, Ruhl et al. (1987) reported that a pause procedure in a lecture has been found to improve both short-term recall and long-term retention. Similarly, the impact of student engagement on a broad range of learning outcomes has been reported by different researchers (Astin, 1993; Hake,1998; Redish et al.,1999; Laws et al., 1999). According to Astin (1993), student involvement is one of the major predictors of success in college while for Hake (1998) interactive-engagement methods were responsible for significantly improved student performance in Introductory Physics courses. Findings on the effectiveness of students' active-engagement by Redish et al. (1999) indicate that improved learning gains are due to the nature of active engagement and not to the extra-time spent on a topic or lessons. Laws et al. (1999) compared active engagement and traditional instruction in terms of conceptual understanding and reported that the effectiveness of active engagement methods surpass traditional instruction.

Studies by Johnson, Johnson and Smith (1998) and Springer et al.(1999) summarize the impact of collaborative and cooperative learning on student performance. According to these studies, collaborative and cooperative learning improved academic achievement, quality of interpersonal interactions, self- esteem, perceptions of greater social support, liking among students, student attitudes, and retention in academic programs.

Problem based learning, as another dimension of active learning, is implemented or practiced in various forms (Prince, 2004). Irrespective this, however, there is at least a generally accepted finding that problem-based learning produces positive student attitudes (Prince, 2004; Vernon and Blake, 1993; Norman and Schmidt, 2000). Moreover, evidences also indicate that problem-based-learning enhances long-term retention of knowledge in comparison to traditional instruction and improves study habits among students. Such habits include increased library use, text booking reading, class attendance, and studying for meaning rather than recall (Norman and Schmidt, 2000; Martensen et al., 1985; Gallagher, 1997). In the current study the following are included as measures of student performance: Child attitudes, self-confidence and job aspirations.

\subsection{Implementation of Active Learning}

Practicing and promoting active learning methods pose enormous challenges in the classroom. According to Alexander (2000) and UNESCO (2004) four broad categories of challenges can be identified: teacher training, material conditions, curriculum and culture.

Issues related to teacher training revolve around the quantity/quality of pre-service preparation and the effectiveness of in-service professional development that teachers receive. Leu (2005) points that in many countries pre-service teacher education is based on traditional models while the curriculum is changing to constructivist approaches based on child centred pedagogies. While this mismatch between the level of teachers' prior education and training represents a challenge to efforts to promote the use of active-learning, research indicates that such challenges can be overcome. Evidences from studies conducted by AIR (American Institute for Research) and Academy for Educational Development (AED) under the EQUIP1 indicate that in-service education programs - especially ones which are school- and school cluster-based, extended over a period of time, and actively engage participants in learning and doing - can develop the commitment and knowledge of even less formally educated teachers that is a pre-requisite for implementing active-learning, student centered pedagogies (Abd-El-Khalick et al., 2006; Amare Asgedom et al., 2006; Barrow et al. 2006; Rocha 2006; Van Graan and Leu 2006).

Material conditions (poor facilities, equipment, and number of students) in classrooms where teachers are asked to implement active-learning pedagogies may certainly be significant determinants of learning. According to a study in Uganda by Siraj-Blatchford et al. (2002) the utilization of childcentered pedagogy was more sporadically implemented both because of the inadequacy of the furnishing and equipment in the classroom and because of large classes.

Another source of challenge for implementing active learning methods emanate from the mismatch between the information-memorization orientation of the curriculum and examinations and the constructivist notions of knowledge and understanding associated with active-learning (AIR and AED, 2006). Parents and other key stakeholders may not believe that the use of active learning would 
enable their children to succeed in their schooling given the demands of the curriculum and examinations for memorization and rote learning. As Hopkins (2002) observes from case studies in Uganda, Kenya and Tanzania, one of the threats to child-centered learning is the narrowing of the definition of effective student learning to test scores. Teachers in these countries are subject to significant expectations and pressure to ensure student success on national examinations rather than understanding their lessons.

Active-learning methods are built on cultural value of relatively democratic or egalitarian (i.e., less authoritarian and unequal power) relations between adults and youth. As various studies (Bernstein, 1971; Eggleston, 1977; AIR and AED,2006) indicate, however, this might contradict with cultural values where authoritarian cultures predominate or there exists (dis) continuity between home or school cultures. For instance, Bernstein (1971) indicates how it may be easier to implement activelearning and student-centered pedagogies for teachers serving working class families than it is for teachers serving middle class families while AIR and AED (2006) indicate that implanting active learning methods are challenging in Islamic and Confucian-influenced cultures.

\subsection{Challenges in Active Learning Research}

Prior to researching problems surrounding active learning methods, it is important to appreciate some methodological challenges. One of this has to do with the confusion that can arise from precisely defining what is being studied. As already discussed elsewhere, there are many approaches that can be put under the umbrella of active learning. Other important problems relate to issues of measurement of what works. According to Prince (2004) four basic issues can be considered.

The first one of these refers to the need to measure multiple outcomes of active learning. Prince argues that when asking whether active learning works, the broad range of outcomes should be considered such as measures of factual knowledge, relevant skills and student attitudes, and pragmatic items as student retention in academic programs. However, this author says that solid data on how an instructional method impacts these learning outcomes is often not available, making comprehensive assessment difficult.

The second significant problem related to measurement, according to Prince (2004) is that many relevant learning outcomes are simply difficult to measure. This is particularly true for some of the higher-level learning outcomes that are targeted by active learning outcomes. The third problem with active learning research has to do with misinterpretation of results. Prince says that even when data on higher level outcomes are available; it is easy to misinterpret reported results.

Another major problem is in determining the significance of improvement caused by active learning. Proponents of active learning sometimes cite improvements without mentioning that the magnitude of improvement is small. According to Prince (2004) this is particularly misleading when extra effort or resources are required to produce an improvement. As a cautionary note, Prince (2004) warns that some reports/readers may dismiss improvements from active learning as Hawthorne effects whereby subjects knowingly react positively to any novel intervention regardless of its merit.

\subsection{Active Learning and Problems of its Implementation in Ethiopia}

The most common characteristics of educational reforms under three different systems of governance (imperial, socialist, federal) in Ethiopia were their emphasis on the relevance of curricula and learning methods. The point of departure for the imperial educational policy was the incorporation of the "Ethiopian" dimension to education in addition to learning foreign languages (Negash, 1990). The educational policy of the military socialist regime was predicated on the rational that the educational policy of the imperial system was too elitist, academic, theoretical and non-productive. In the new framework, the role of education among other things was to integrate education with production (see McNab, 1989; Negash, 2006). A significant shift to constructivist educational approach and learning methods was made by the Federal Republic in its policy documents. In its Education Sector Strategy (1994), the federal emphasized that the teaching-learning process shall emphasize problem solving by making the curriculum more relevant and by adopting appropriate teaching methods.

Very few credible studies exist about how much active learning is implemented in classrooms. Some studies try to address the problem using guised approaches. For instance, Dufera (2007) studied the tension between innovative and traditional approaches in classrooms and concluded that traditional 
approaches still dominate the didactic process. Melese et al. (2010) investigated the practice of learner-centred methodology in upper primary school of Ethiopia and revealed that upper primary school teachers try to employee learner centred methodology in the classroom even though it is not adequate. Desta et al. (2010) quasi-experimented whether or not self and peer reflection enhance active learning in classrooms and they reported that these techniques were accepted by practitioners. The outcome of a longitudinal study on active learning practices and behaviours in USIAD supported schools and teacher education colleges were reported by USAID (2007). This report indicates active learning behaviours indeed practiced in these institutions but traditional methods continue to strongly prevail.

\section{Methodology}

\subsection{Design and Procedures}

Within the Young Lives Research on Mathematics Education in Ethiopia, this study used survey research combined with field observations and questionnaires. The study involved directly obtaining information from many teachers and students through observations and by administering questionnaires outside the class. There were two types of observations in the classroom: student observation and teacher observation.

Recording student activities were conducted through timed observations. A list of Young Lives case study children in each class, whom an observer was supposed to observe, was prepared. A maximum of two observers were assigned to each class and the first observer used the list to select up to six Young Lives case study children for timed observation in each class. If an observer had fewer than six Young Lives children in each class, s/he was requested to observe as many Young Lives children as $\mathrm{s} / \mathrm{he}$ may have in the class. The observer was requested to balance between boys and girls.

Each selected child was observed in turn during a two-minute period and a decision was taken about the coded activity in which she or he was involved at that particular moment. Each child was observed for about 10-15 seconds, and the observer decided which code best describes what the child is doing, entered it in the table prepared for the purpose and then look at the next child. Once an observer has observed and recorded all six children's activities (which takes about 90 seconds), she or he waited until the beginning of the next two-minute interval and started back at the beginning again with Student 1 . If the child is doing the same activity as before, he entered the same code. If they are doing a different activity, the observer entered the new code. It was important that the observer watched the children in the same order each time. Observers were also requested to try to avoid eye contact with the students they were observing, and try to make sure they aren't aware they are being observed.

A second observer was required to observe the activities of the teacher in the same classroom. Teacher's main activities were recorded at one minute intervals over the course of 30 minutes. The activities were classified into three main categories already described previously. Like in the student observations, a format was provided in which the activity code was entered in correspondence with the observation time for record keeping.

\subsection{Instruments of Data Collection}

Data from three types of instruments were used for the current purpose: child observation formats, teacher observation formats and child questionnaires. The child observation format was designed to record student behaviour in the process of classroom observation. It has three sections. The first section is dedicated to recording general information. The second section provides space for registering a maximum of 18 Young Lives students selected for observation. The third section provides a format for entering activity codes and the child ID together with the time of observation.

The teacher observation format is similar with that of students except for the long list of activities to be observed over 30 times within a given lesson. Observers were given about 13 activity codes to which they enter "yes" or "no" depending upon the prevalence of the expected activity.

Child questionnaires were of two types: Grades 1-4 and 1-8. In principle, these questionnaires were similar in their content and the main purpose for using them was to measure student attitudes, self confidence and aspirations. Both have many items, but items relevant to this article were selected.

\subsection{Samples and Data Analysis}

The observational nature of this study has made the sampling procedure purposive. Young Lives students and teachers were purposely included in the study. Thus, the findings of the study are 
generalizable only to the samples covered and the subject observed. The 20 communities within which the Young Lives Project researches Mathematics education provided the general geographical area from which samples were selected in this study. The main sampling units were the total number of valid teacher and student observations while the number of students who were included to provide information in child's questionnaire was also sampling elements. The planned total number of teacher observations was 75,090 , but the total number of valid observations made was 57,900. A similar number of targets were set for student observations although the obtained number of valid observations was 26,852. For child questionnaire G1-4 and G1-8, the total number of targeted samples was 2,530 each, but what were obtained were 1,203 for each group.

Data was analyzed using frequency tables as the main purpose of the study is largely description. Survey methodology provided a larger basis of data to understand the practice of active learning in the classroom. The multitude of categories created for recording data has given in-depth information to assess the level of implementation of these methods in (Mathematics) classrooms.

\section{Findings And Presentation of Data}

\subsection{Student Participatory Activities}

Observers were guided to observe behaviours categorized into three typologies: teacher-oriented whole sale activities, child-centred activities and off task activities. Regarding teacher-oriented student activities the following were observed: listening/watching the teacher, offering to answer questions, chanting in unison, making contribution to the lesson and writing in exercise books. Child - centred activities observed when students were engaged in individual task/activity, group task or activity and conversation with the teacher. Similarly, students were observed during off task activities which included engagement in alternative activity, sleep/day dreaming and disciplinary corrections. Summary of the results are as follows.

Table1. Summary of student activities/behaviors in the classroom

\begin{tabular}{|l|l|l|l|l|}
\hline $\begin{array}{c}\text { Total } \\
\text { Observation } \\
\text { Time }\end{array}$ & \multicolumn{1}{|c|}{ Observed student activity/behaviour } & $\begin{array}{c}\text { Number of } \\
\text { Observations } \\
(\mathrm{N})\end{array}$ & Frequency & \multicolumn{1}{|c|}{$\begin{array}{c}\text { Valid } \\
\text { Percent }\end{array}$} \\
\hline 14 & Listening/watching teacher & 26,854 & 9,964 & 37.10 \\
\hline 14 & Offering to answer question/instruction & 26,854 & 1,792 & 6.67 \\
\hline 14 & Chanting in unison & 26,854 & 1,582 & 5.89 \\
\hline 14 & Responding/making a contribution to the lesson & 26,854 & 1,060 & 3.94 \\
\hline 14 & $\begin{array}{l}\text { Writing/drawing in exercise books and on } \\
\text { individual slates }\end{array}$ & 26,854 & 4,560 & 16.98 \\
\hline 14 & Individual task/activity & 26,854 & 1,661 & 6.16 \\
\hline 14 & Group task/ activity & 26,854 & 627 & 2.33 \\
\hline 14 & Conversation/with the teacher & 26,854 & 236 & 0.88 \\
\hline 14 & Engagement in alternative off task/activity & 26,854 & 2,904 & 10.8 \\
\hline 14 & Being in disciplinary corrections & 26,854 & 33 & 0.12 \\
\hline
\end{tabular}

The above table suggests that active listening and/or watching is the most dominant behavior in the classroom. It occurred $37.1 \%$ and it means that teacher activities which demand student attention are still dominant over student - centered activities. This is not consistent with USAID (2007) report, which claims that "asking questions by the teacher and giving responses "were the dominant trends in USAID supported schools. Writing is the second most important task that sets students for active participation in the lesson. Such activities as copying notes from blackboard, writing down teacher's dictation, or completing other tasks accounted for about $17 \%$ of the activities.

If vivid active learning behaviors are not taking place as expected in lessons, one would be tempted to think that other or off task activities are occurring in the classroom. In deed, it is interesting to observe in the above table that the third groups of activities engaging students were off task activities. Observers recorded such activities as playing a game under the desk or chatting with friends (not related to learning) or engaging in disruptive activity (e.g. shouting, fighting, and teasing other children) were significantly prevalent in the classroom. They accounted for about $11 \%$ of student behaviors. In comparison to other major activities in which only few number of students get involved, the strength at which off task activities involve learners is higher. The occurrence of off task can be 
explained by a variety reasons, but lack of attractiveness of instruction and the incompetence of teachers to engage all learners can be just few of them.

In this study, students offering behavior like readiness to answer questions by, for instance, raising hands was not as high, but it accounted about $8 \%$ of the observations. For students to offer answers, it is important that teachers offer problem-based learning or instruction. What this finding suggests is that lessons are not based on problem - solving approach in such important subject as mathematics where one can expect questions and answers at any time in the lesson.

Similar low profile engagement of students can also be noticed in their participation in chanting in unison, individual and group activities as well as with conversation with the teacher. Commonly these would have been the best opportunities for students to be active in the classroom but they are rarely taking place. The extent to which students are disciplined (being scolded, threatened with physical punishment, or beaten by teachers) can also be an indirect indicator of how much active learning is taking place in the classroom. The more disciplining takes place by the teacher, the less is the child's active participation in learning. In this respect the current finding shows that disciplining students is not a common occurrence among students.

\subsection{Variations of Student Classroom Activities}

It is possible that student active participation in classroom learning will vary among groups. The following tables describe the variations of student activities in the classroom based upon their gender and location.

Table2. Student active participation by gender and location

\begin{tabular}{|l|c|c|c|c|}
\hline \multirow{2}{*}{\multicolumn{1}{|c|}{ Observed student activity/behaviour }} & \multicolumn{4}{|c|}{ Variation by } \\
\cline { 2 - 5 } & \multicolumn{2}{|c|}{ Gender } & \multicolumn{2}{c|}{ Location } \\
\cline { 2 - 5 } & $974(77.4 \%)$ & $936(79.9 \%)$ & $695(84.0 \%)$ & $1,215(75.8 \%)$ \\
\hline Listening/watching teacher & $973(77.3 \%)$ & $937(79.9 \%)$ & $695(84.0 \%)$ & $1,215(75.8 \%)$ \\
\hline Offering to answer question/instruction & $974(77.4 \%)$ & $937(79.9 \%)$ & $697(84.3 \%)$ & $1,214(75.7 \%)$ \\
\hline Chanting in unison & $975(77.5 \%)$ & $936(79.9 \%)$ & $697(84.3 \%)$ & $1,214(75.7 \%)$ \\
\hline $\begin{array}{l}\text { Responding/making a contribution to the } \\
\text { lesson }\end{array}$ & $974(77.4 \%)$ & $937(79.9 \%)$ & $697(84.3 \%)$ & $1,214(75.7 \%)$ \\
\hline $\begin{array}{l}\text { Writing/drawing in exercise books and on } \\
\text { individual slates }\end{array}$ & & & & \\
\hline Individual task/activity & $975(77.5 \%)$ & $937(79.9 \%)$ & $697(84.3 \%)$ & $1,214(75.7 \%)$ \\
\hline Group task/ activity & $974(77.4 \%)$ & $937(79.9 \%)$ & $697(84.3 \%)$ & $1,214(75.7 \%)$ \\
\hline Conversation/ with the teacher & $975(77.5 \%)$ & $937(79.9 \%)$ & $697(84.3 \%)$ & $1,215(75.8 \%)$ \\
\hline Engagement in alternative off task/activity & $975(77.5 \%)$ & $937(79.9 \%)$ & $697(84.3 \%)$ & $1,215(75.8 \%)$ \\
\hline Being in disciplinary corrections & $974(77.4 \%)$ & $937(79.9 \%)$ & $697(84.3 \%)$ & $1,213(75.7 \%)$ \\
\hline
\end{tabular}

Regarding gender, Table 2 above shows that females have more active participation than males across all specific behaviors observed. One would expect under these circumstances that the academic performance of students will follow patterns. However, both the Second (MOE, 2004) and Third (MOE, 2007) Ethiopian National Learning Assessments indicated that males achieved more than females. Further insights are required to understand why gender seems to have less or no relevance to active learning methods and indirectly to achievement. On the other hand, the table shows that urban students are participating more in classroom activities than rural students. Unlike findings in relation to gender, this one is consistent with the assumption that urban students' higher participation corresponds with superior scholastic achievement. Indeed, both the Second (MOE, 2004) and Third (MOE, 2007) Ethiopian National Learning Assessments indicated that urban students academically achieved more than rural students.

\subsection{Teachers Practical Activities in the Classroom}

Overall teacher activities were classified into the following during observations: explaining a lesson, lecturing, group call and response, questioning and setting work, discussion, guiding group work and the individual student. Other activities observed included discipline, administration, marking work, chatting and temporary absence.

Teacher's explanation behavior involves lesson introduction and commenting. Lecturing involves teacher's delivery of a lesson while group call-and-response behaviors refer to teachers asking of questions and students chanting response in chorus. In setting work, a teacher asks children to solve 
problems from the blackboard while in the discussion session s/he is expected to ask students openended questions or discuss the lesson with them. In guiding an individual or group work, a teacher is expected to instruct and interact with an individual student or students in small group respectively.

A teacher is considered disciplining students when s/he is involved in scolding, punishing or threatening them. A teacher who does administrative work may be observed to have been involved in reporting writing, organizing teaching materials etc. A teacher is considered to have been engaged in feedback if s/he has been marking students' written work in their note books or work books. Chatting behavior of teachers refers to talking with others in the classroom while absenteeism refers to temporary walkouts from the class.

Table 4 below summarizes results from the analyses each of the activities. In the table, it is clear that teacher's prologue to the lesson, his or her explanation of the focal points the lesson, presentation of his or her main activities or strategies in the lesson as well as summaries and conclusions were recorded "no" in $93.5 \%$ of the observations. This means, in most cases teachers were observed to have made no explanations of lessons to their students. This finding is astonishing given the role an explanation to a lesson plays in positively motivating and orientating students. Unless learners are shown their directions in lessons, it is very difficult for them to have clarity of purpose.

Table3. Teacher activities in the classroom

\begin{tabular}{|l|l|l|l|l|l|l|}
\hline \multirow{2}{*}{$\begin{array}{c}\text { Total } \\
\text { Observation } \\
\text { Time }\end{array}$} & & \multicolumn{2}{c|}{ Yes } & \multicolumn{3}{c|}{ No } \\
\cline { 3 - 6 } & Observed teacher activity/behaviour & & Frequency & Percent & Frequency & Percent \\
& & & & & \\
Total \\
\hline 30 & Explaining lesson & 3736 & 6.5 & 54164 & 93.5 & 57900 \\
\hline 30 & Lecturing & 11,165 & 19.28 & 46,735 & 80.72 & 57,900 \\
\hline 30 & Group Call & 6,790 & 88.27 & 51,110 & 11.73 & 57,900 \\
\hline 30 & Questioning individual students & 11,904 & 20.60 & 45,996 & 79.44 & 57900 \\
\hline 30 & Setting Work & 5,988 & 10.34 & 51,912 & 89.65 & 57900 \\
\hline 30 & Discussion/interaction with students & 3,784 & 93.5 & 54,116 & 6.5 & 57900 \\
\hline 30 & Guiding Group Work & 2,016 & 3.5 & 55,884 & 96.5 & 57900 \\
\hline 30 & Guiding individual students & 4,520 & 7.80 & 53,380 & 92.2 & 57,900 \\
\hline 30 & Disciplining students & 837 & 1.45 & 57.063 & 98.55 & 57900 \\
\hline 30 & $\begin{array}{l}\text { Engagement in administrative } \\
\text { activities }\end{array}$ & 398 & 0.69 & 57,502 & 99.31 & 57900 \\
\hline 30 & $\begin{array}{l}\text { Engagement in feedback activities of } \\
\text { written assignment }\end{array}$ & 2,957 & 5.1 & 54,943 & 94.9 & 57900 \\
\hline 30 & $\begin{array}{l}\text { Chatting with other staff or mobile } \\
\text { and waiting the lesson to end }\end{array}$ & 1,922 & 3.3 & 55,978 & 96.7 & 57900 \\
\hline & $\begin{array}{l}\text { Temporary absence or walk out from } \\
\text { the classroom }\end{array}$ & 88 & 0.2 & 57,812 & 99.8 & 57900 \\
\hline
\end{tabular}

The above table, in general, shows that teacher behaviors are in transition, but, far from being the dominant trend in classrooms. Obviously, teacher explanation in which the teacher serves as the sole source of information is very low. Similarly, Table 4 above shows that lecture is not used in most of the classes as more than $80 \%$ of the observations during the 30 minutes' observation-time were not focused around it. It is well known that lecture is a one-way communication strategy unless otherwise special measures are taken to make it an active learning strategy. Given these requirements and the complexity of skills required of teachers to convert lectures into an active learning strategy, it seems positive to see the limited use of lectures in primary school education in the Ethiopian context.

Group call by the teacher can be a significant strategy of active learning to simultaneously provide opportunities to many pupils to participate in classroom activities. Students could be abele to chant responses in chorus to a question from the teacher. From the table, it is clear that of the total observations recorded $(\mathrm{N}=57,900), 88.27 \%$ did involve in group call and response activities by teachers. In a large class context like in Ethiopia, group call and response can be an appropriate technique to make students active since it does not take much time and effort to get student involvement. 
Teachers can also create a vibrant classroom by asking individual students to contribute to the lesson using such techniques as asking child to answer question to the whole class, solve a problem or write an answer on the blackboard in front of the whole class. Such an approach can contribute to the development of self-confidence in students and to encourage them to demonstrate their work and capacities to their peers. Results summarized in Table, show that teachers were observed for not using this technique in $79 \%$ of the observed lessons. In fact, this activity has been traditionally practiced in schools before an official policy was adopted to use active learning methods in Ethiopia. One reason why teachers may have reduced the use this method can be due to their focus on group calls.

Assigning students to such tasks as solving problems from the blackboard, complete a written or verbal test, worksheet etc. in the classroom can serve as monitoring and feed back mechanisms in learning. From the table, out of the total observations $(\mathrm{N}=57,900)$ made in all schools under investigation, it was only in 5,988 or $10 \%$ of them that teachers were observed to set work in the classroom for students to be completed during the lesson. One can argue that such circumstances can be the result of poor classroom facilities, large class size etc. However, teacher competence, motivation and concern can be more responsible for such state of affairs than the mentioned factors. This is because setting work in the classroom is a common practice even in the traditional teacherdominated classrooms.

Teacher interaction with students is vital in any learning process. In the above table teacher communication with students has been observed to have taken place 3,784 times out the 57,900 observations recorded. This was $6.5 \%$ of the total. Why teachers are not involved in asking questions about the lessons may be a matter of attitude where students are not considered to provide an adequate analysis of a lesson.

Group work is a form of cooperative learning which maximizes student's own and other members' ability to learn in small groups. Teachers form groups, guide these groups by interacting with members and/or help them to solve problems. In the current study, the degree to which teachers were involved in guiding small groups of students was too low. It was $3.5 \%$ out of the total as indicated in the table above implying the non- existence of small groups in most schools. The table also shows that teacher interaction and guidance of individual students was about $8 \%$ and this is better than the $3.5 \%$ observed for group guidance. Individual interaction of teachers with students may be undermined by the large number of students in a single classroom. It takes both time and energy to correct papers, give feedback or talk to the individual child.

Coercive discipline by teachers was one of the targets of observation in this study. Observers were requested to record teacher involvement in such activities as scolding, punishments or threats to punishments. As it has been reported earlier under student observations, exercising coercive discipline does not imply active learning, but the lack of it. In the table above, the prevalence of only 837 coercive acts out of 57,900 shows that a constructive discipline is exercised in classrooms. Involvement in coercive discipline was $1.45 \%$ of the total.

Teacher's engagement in administrative tasks while the classroom is going on can be considered as a non-active behavior. This is because administrative tasks other than checking student attendance are expected to be completed before or after lessons. Findings in the above table seem to be consistent with this assumption. The table shows that teacher administrative activities are not taking place in the classroom. Out of 57,900 observations, it is only 389 times or $0.69 \%$ that teachers were seen to have been engaged in administrative matters in the classroom.

On the other hand, teacher feed back at any point in lessons is an important element to follow up student improvements, encourage and motivate them. It also serves to instruct correct behavior and inculcate skills. Summaries from these observations indicate that teacher feedback activity has taken place 2,957 times or $5.1 \%$ out of the 57,900 total observations recorded. This shows that feedback is not widely exercised among teachers although its methodological value is significant both for teachers and students. Perhaps, the large class size might contribute to such circumstances because it can take longer time to complete such task in the class or outside.

Teachers chatting and waiting for lessons to end does not represent active learning, but its absence does indicate active engagement by the teacher. Whether teachers were talking with other staff (in the classroom), answer mobile phones or do nothing but wait for the lessons to end/bell to ring/ was assessed in this study, but results in the above table shows that this behavior occurred 1,922 times (3.3\%) out of 57,900 observations. Numerically, this behavior does not seem significant among 
teachers, but its prevalence by itself is quite damaging to the educational system. Improving the situation calls for stronger school management and supervision. It also requires capacity building among teachers particularly those who hadn't been trained in how to use active learning methods.

Leaving the classroom before the end of lessons or during lessons by teachers does not help the cause of active learning by students. Teacher absenteeism represents the wastage of instructional time and a direct deprivation of students from learning. Findings from the analysis of data in the above table indicate that temporary absenteeism of teachers was very negligible in the observations. It has occurred only 88 times $(0.2 \%)$ out of the total of 57,900 observations. Teachers may be temporarily absent due to meetings, settlement of conflicts among students if they happen, reception of guests etc.

\subsection{Student Attitudes, Self-Confidence and Job Aspirations}

Although the most common way to measure student performance is through academic achievements using standardized tests, it is also possible to see their attitudes as general indicators of success in schooling. In the current study, it was not possible to access credible data on students' academic achievement in the Young Lives project. However, the project has measured student attitudes using a "Child Questionnaire" in both Lower Grades (G1-4) and Second Cycle (G5-8) primary schools.

Table4. Grade 1-4 Student attitudes, self-confidence and aspirations

\begin{tabular}{|c|c|c|c|c|c|c|}
\hline \multirow[t]{2}{*}{ No } & \multirow[t]{2}{*}{ Attitudinal Statements } & \multicolumn{5}{|c|}{$\begin{array}{l}\text { Level of agreement } \\
(\mathrm{N}=1203)\end{array}$} \\
\hline & & Agree $(\%)$ & Disagree & Both & None & $\begin{array}{l}\text { Refused } \\
\text { to answer }\end{array}$ \\
\hline 1 & I enjoy the work I do in my class & $1025(85.2 \%)$ & $516(13 \%)$ & $16(1.3 \%)$ & $5(0.4 \%)$ & $1(0.1 \%)$ \\
\hline 2 & $\begin{array}{l}\text { I am eager to go to school } \\
\text { everyday }\end{array}$ & $1008(83.8 \%)$ & $181(15 \%)$ & $8(0.7 \%)$ & $4(0.3 \%)$ & $2(0.2 \%)$ \\
\hline 3 & School is boring & $368(30.6 \%)$ & $817(68 \%)$ & $8(0.7 \%)$ & $5(0.4 \%)$ & $4(0.3 \%)$ \\
\hline 4 & My maths class is enjoyable & $968(80.5 \%)$ & $221(18.4 \%)$ & $8(0.7 \%)$ & $4(0.3 \%)$ & $2(0.2 \%)$ \\
\hline 5 & $\begin{array}{l}\text { Maths classes are so difficult that } \\
\text { they can only be done by the most } \\
\text { intelligent students }\end{array}$ & $689(57.3 \%)$ & $504(41.9 \%)$ & $2(0.2 \%)$ & $4(0.3 \%)$ & $4(0.3 \%)$ \\
\hline 6 & $\begin{array}{l}\text { My teacher goes out of his/her way } \\
\text { to hep me }\end{array}$ & $882(73.3 \%)$ & $298(24.8 \%)$ & $13(1.1 \%)$ & $9(0.7 \%)$ & $1(0.1 \%)$ \\
\hline 7 & $\begin{array}{l}\text { My teachers care about their } \\
\text { students }\end{array}$ & $985(81.9 \%)$ & $200(16.6 \%)$ & $8(0.7 \%)$ & $6(0.5 \%)$ & $4(0.3 \%)$ \\
\hline 8 & $\begin{array}{l}\text { In my class, everybody is my } \\
\text { friend }\end{array}$ & $752(62.5 \%)$ & $432(35.9 \%)$ & $10(0.8 \%)$ & $6(0.5 \%)$ & $3(0.2 \%)$ \\
\hline 9 & $\begin{array}{l}\text { Sometimes my maths teacher } \\
\text { shames students for not knowing } \\
\text { the right answer }\end{array}$ & $678(56.4 \%)$ & $512(42.6 \%)$ & $6(0.5 \%)$ & $5(0.4 \%)$ & $2(0.2 \%)$ \\
\hline 10 & $\begin{array}{l}\text { Students in my class have good } \\
\text { relationships with each other }\end{array}$ & $978(81.3 \%)$ & $208(17.3 \%)$ & $7(0.6 \%)$ & $8(0.7 \%)$ & $2(0.2 \%)$ \\
\hline 11 & $\begin{array}{l}\text { Children in our class fight most of } \\
\text { the } \\
\text { time }\end{array}$ & $555(46.1 \%)$ & $624(51.9 \%)$ & $9(0.7 \%)$ & $5(0.4 \%)$ & $10(0.8 \%)$ \\
\hline 12 & $\begin{array}{l}\text { I can do my work at school without } \\
\text { help }\end{array}$ & $756(62.8 \%)$ & $433(36.0 \%)$ & $6(0.5 \%)$ & $6(0.5 \%)$ & $2(0.2 \%)$ \\
\hline 13 & $\begin{array}{l}\text { Some of the students in my class } \\
\text { always want to do things their own } \\
\text { way. }\end{array}$ & $838(69.7 \%)$ & $348(28.9 \%)$ & $9(0.7 \%)$ & $4(0.3 \%)$ & $4(0.3 \%)$ \\
\hline 14 & $\begin{array}{l}\text { If I study hard at school I will get } \\
\text { good results }\end{array}$ & $1086(90.3 \%)$ & $109(9.1 \%)$ & $2(0.2 \%)$ & $4(0.3 \%)$ & $2(0.2 \%)$ \\
\hline 15 & $\begin{array}{l}\text { If I study hard at school I will have a } \\
\text { better job in the future }\end{array}$ & $1048(87.2 \%)$ & $142(11.8 \%)$ & $8(0.7 \%)$ & $3(0.2 \%)$ & $1(0.1 \%)$ \\
\hline
\end{tabular}

The Child Questionnaire contained many items, but for the current purpose items that focused on student attitudes towards the school, school subjects (i.e. Maths in this case), teachers and fellow students were selected. Moreover, items that focused on student job aspiration and self-confidence were also included. Results for these two levels of students are summarized in Table 5 above.

The first three statements in the table were used to understand how students feel about schooling in general. Two of the statements are positive while one of them was stated in negative. In all the three 
statements, majority of students expressed positive outlooks towards schooling. This is not astonishing given the incentives for schooling nationwide.

The next two statements were meant to assess what students think of school subjects as exemplified by their opinions about Mathematics. It is interesting to see that most students said they enjoy their mathematics class, but it is too difficult for most of them. In reality, too difficult subjects can not be enjoyed and the second statement seems to represent the reality of students. At least, we can learn from here that the appropriateness of the curriculum is still a challenge for students to perform well in schools.

Items 6, 7 and 8 were statements posed to lower grade students to find out what they think of teachers. While majority of students are positive about teachers care and support, majority of them were astonishingly dissatisfied with teacher actions to embarrass them for not correctly responding to questions by teachers. This is again a good indicator of the inappropriate relationship between teachers and students and the fact that student performance is not as expected (if of course they couldn't correctly answer).

The three statements regarding student attitude towards fellow-students focused on friendliness, general relations among students and whether students frequently conflict with others. Results show that majority of students are good friends to each other and conflicts among them are not significant at this level. Since students are very young at this stage such responses are expected.

Students self-confidence were indirectly assessed using statements that refer to whether or not they could do their work without help, could do things in their own ways and if they relate their hard work with higher achievements. Again, majority of students have expressed positive opinions about themselves. But, it is very questionable, for instance, how they would do their work without help if the curriculum is difficult as they have reported. And the last question proposed to them was meant to assess their aspirations with learning in which majority of them expressed the need for hard work to get a better job in the future.

Table5. Grade 5-8 student attitudes, aspirations and self-confidence

\begin{tabular}{|c|c|c|c|c|c|c|}
\hline \multirow[b]{2}{*}{ No } & \multirow[b]{2}{*}{ Attitudinal Statements } & \multicolumn{4}{|c|}{ Levels of agreement $(\mathrm{N}=1203)$} & \multirow[b]{2}{*}{$\begin{array}{c}\text { Refused to } \\
\text { answer }\end{array}$} \\
\hline & & Agree $(\%)$ & Disagree & Both & None & \\
\hline 1 & I enjoy the work I do in my class & $837(93.1 \%)$ & $60(6.7 \%)$ & $1(0.1 \%)$ & $1(0.1 \%)$ & $0(0 \%)$ \\
\hline 2 & I am eager to go to school everyday & $633(70.4 \%)$ & $266(29.6 \%)$ & $0(0 \%)$ & $0(0 \%)$ & $0(0 \%)$ \\
\hline 3 & School is boring & $72(8.0 \%)$ & $825(91.8 \%)$ & $0(0 \%)$ & $0(0 \%)$ & $2(0.2 \%)$ \\
\hline 4 & My maths class is enjoyable & $143(15.9 \%)$ & $754(83.9 \%)$ & $1(0.1 \%)$ & $0(0 \%)$ & $1(0.1 \%)$ \\
\hline 5 & $\begin{array}{l}\text { Maths classes are so difficult that they } \\
\text { can only be done by the most } \\
\text { intelligent students }\end{array}$ & $729(81.1 \%)$ & $168(18.8 \%)$ & $0(0 \%)$ & $0(0 \%)$ & $1(0.1 \%)$ \\
\hline 6 & $\begin{array}{l}\text { My teacher goes out of his/her way to } \\
\text { help me }\end{array}$ & $840(93.4 \%)$ & $58(6.5 \%)$ & $1(0.1 \%)$ & $0(0 \%)$ & $0(0 \%)$ \\
\hline 7 & My teachers care about their students & $794(88.3 \%)$ & $103(11.5 \%)$ & $0(0 \%)$ & $0(0 \%)$ & $2(0.2 \%)$ \\
\hline 8 & $\begin{array}{l}\text { Sometimes my maths teacher } \\
\text { embarrasses students for not } \\
\text { knowing the right answer }\end{array}$ & $781(86.9 \%)$ & $118(13.1 \%)$ & $0(0 \%)$ & $0(0 \%)$ & $0(0 \%)$ \\
\hline 9 & In my class, everybody is my friend & $256(28.5 \%)$ & $643(71.5 \%)$ & $0(0 \%)$ & $0(0 \%)$ & $0(0 \%)$ \\
\hline 10 & $\begin{array}{l}\text { The majority of the students in my } \\
\text { class have good relationships with } \\
\text { each other }\end{array}$ & $794(88.3 \%)$ & $103(11.5 \%)$ & $1(0.1 \%)$ & $0(0 \%)$ & $1(0.1 \%)$ \\
\hline 11 & $\begin{array}{l}\text { Children in our class fight most of } \\
\text { The time }\end{array}$ & $496(55.2 \%)$ & $401(44.6 \%)$ & $0(0 \%)$ & $2(0.2 \%)$ & $0(0 \%)$ \\
\hline 12 & $\begin{array}{l}\text { I can do my work at school without } \\
\text { help }\end{array}$ & $73(8.1 \%)$ & $824(91.7 \%)$ & $1(0,1)$ & $1(0.1 \%)$ & $0(0 \%)$ \\
\hline 13 & $\begin{array}{l}\text { Some of the students in my class } \\
\text { always want to do things their own } \\
\text { way. }\end{array}$ & $789(87.8 \%)$ & $109(12.1 \%)$ & $1(0.1 \%)$ & $0(0 \%)$ & $0(\%)$ \\
\hline 14 & $\begin{array}{l}\text { If I study hard at school I will get } \\
\text { Good results }\end{array}$ & $600(66.7 \%)$ & $298(33.1 \%)$ & $1(0.1 \%)$ & $0(0 \%)$ & $0(0 \%)$ \\
\hline 15 & $\begin{array}{l}\text { If I study hard at school I will have a } \\
\text { better job in the future }\end{array}$ & $871(96.9 \%)$ & $26(2.9 \%)$ & $2(0.2 \%)$ & $0(0 \%)$ & $0(0 \%)$ \\
\hline
\end{tabular}


Students in upper primary (G5-8), have expressed agreements with lower primary students, but also different in some important ways. Regarding schooling, they are generally positive as they expressed enjoyment, interest to go to school everyday and that schooling is not boring. However, one can see that the proportion of those who expressed eagerness to go to school everyday is much less than students in lower primary schools. At higher level, this implies, one can see changing attitudes towards schooling by itself.

As Table 6 above shows, most students in upper primary schools expressed that Mathematics classes are not enjoyable and that teachers were embarrassing them if they couldn't respond correctly to teacher questions. Most upper primary students do not also believe that all students in their classes are friendly to them. Similarly, majority of students expressed the prevalence of conflicts among students and that they can not do their work without help.

\section{Summary AND Discussions}

One of the most important innovations Ethiopia adopted since the last two decades includes the shift from traditional instruction to active learning methodologies in the classroom. To implement the innovation, changes in teacher education, text books preparation, school based professional development activities etc. have been introduced. However, the degrees to which these methods are practiced and students benefited are very far from known.

The Young Lives Project has sponsored this study to throw light on the status of active learning practices in Ethiopian primary schools. The study is based on the survey of many lessons and teachers in its operational areas mainly using field observations. Teacher and student activities were the main units of observations.

Findings suggest that the extent to which students actively participate in the classroom is dominated by listening and watching the teacher. Whether this activity is entirely active by itself is very debatable. Even though low, the second most important activity is writing or copying from the blackboard or teachers dictation. Again, this is a method which was very much at the center of the old teacher-centered approach to instruction. Astonishingly other methods including offering to answer question, chanting in unison, contributing to lessons etc. have been rarely exercised and a significant amount of time is wasted by off task activities. Braxton, Milem and Sullivan (2000) indicate that the effectiveness of active learning in relation to student success depends on both exogenous and indigenous variables. The exogenous factors define student entry characteristics which, in turn, affect commitment to learning or the institution of learning. These entry characteristics include family background, individual attributes and preschool experience. It should be remembered that findings from the Third Ethiopian National Learning Assessment (MOE, 2007) has demonstrated such background factors as parent's educational background, ability to avail resources, proper meals, academic support etc. to have relations with student performance. Similarly, the same study has shown that such individual attributes as student self-concept, medium of instruction; gender and location have been very influential in student achievements. Endogenous factors that influence the effectiveness of active learning among students according to Braxton, Milem and Sullivan (2000) include institutional type, organizational attributes, motivations, job satisfaction, social integration etc. In Ethiopia, school characteristics matter in what students achieve and per Third Ethiopian National Learning Assessment (MOE, 2007) these include the curriculum, teachers, school management, instructional materials support etc. Thus, the essence of low participation of students in the classroom must be understood in a wider sense by considering factors both inside to students as well as outside of them.

Regarding teachers, it is obvious that teacher behaviors are in transition. On the one hand, there are departures from the traditional old practices such as lectures or explanations. On the other hand, teachers were not able to fully to implement the new methods. Only some group calls and individual guidance activities also take place at a lower level. Very clearly, adherence to old approaches are still dominant and the fundamental theory of making learning "social" is eluding the observed schools. According to Alexander (2000) there are many challenges for teachers to promote the use of activelearning, student-centered pedagogies. These include the quantity/quality of pre-service preparation and the effectiveness of in-service professional development that teachers receive, the material conditions (facilities, equipment, and number of students) in classrooms where teachers are asked to 
implement active-learning pedagogies, the inconsistency between the information-memorization orientation exemplified in the curriculum and examinations (focusing on memorization of information) and the constructivist notions of knowledge and understanding associated with activelearning, and the cultural appropriateness of the model of adult-child-knowledge relations on which active-learning pedagogies are based. In deed, the Third Ethiopian National Learning Assessment (MOE, 2007) indicated that several teacher variables influence effective learning in schools. Among these it includes in-service professional development, heavy workload, availabilities of such facilities as pedagogical centers, clinical supervision, on- job-training and others.

Braxton, Milem and Sullivan (2000) recognize that the classroom is a key gateway to what students achieve in terms of commitment to learning, failure or social integration. Since what happens to students in schools is also very much dependent on what happens in the classroom, it is obvious that much has not been observed in terms of the development of desirable attitudes, self-confidence and future aspirations in the current study. This is again consistent with Stockard and Mayberry (1996) who argue that effective learning environments are the interplay of very many factors including the policy environment, structure of learning, school and classroom environment, school resources and classroom conditions. In Ethiopia, the policy environment is clearly supportive of active learning and student-centered pedagogies. However, the observed low level of participation of students in classroom activities and teachers practice to implement active learning methods can be viewed within a framework related to endogenous and exogenous factors to learners and teachers, and that can be subsumed into the debate of creating effective learning environments.

\section{IMPlications FOR Policy}

Any instructional method can not be implemented without the interaction of teachers and students at the classroom level even if the policy environment is conducive. The current study has clearly shown that the level to which teachers and students practice active learning methods and the formation of student attitudes, self-confidence and aspirations are low. The implication of these findings to policy making and practice can be many, but the most important ones may include the following.

Focus on Teacher Training: Enabling teachers to use active learning methods has to be the focus of change in primary education. This involves formal training and professional development programs. In formal training, to develop the capacity of teacher trainers takes the priority. This is because these trainers by themselves are inadequately trained for the new methodology. Similarly, the curriculum of teacher training has to be revisited including teaching materials and practicum. Most of all, the relationship between primary school curricula and teacher education needs careful examination. Whether the current diploma program is adequate for primary school instruction must be reviewed. Decisions to change the current teacher education structure need to prioritize pedagogic reasons over economic considerations. The changing contents of school curricula may demand more training than what prevails just now. It is also imperative to adequately train future teachers practically in schools. In addition to these, the recruitment of capable and interested candidates is another area which requires revisits. Currently, candidates who couldn't make it to other professions are the ones who are recruited to the teaching profession.

The Need for Conducive Primary School Environments: Primary schools also need to provide the necessary working climate for the implementation of active learning methods. The need to improve on large class size seems imperative in the Ethiopian case. Availability of learning resources and the provision of appropriate incentives and supervision by management seems necessary. Strengthening school-community relations would improve practicum and the assignment of students to schools. The school needs to structure learning in a way that promotes active learning. The lack of group activities needs to be overcome. The school also needs to work on enhancing the communication between teachers and students. It has to work on the egalitarian culture of active learning than the authoritarian approach of traditional approaches.

The Need to Reduce Poverty and Create Capacity at Different Levels: Exogenous factors are very much related to poverty and economic deprivation. While alleviating them requires long term development, immediate issues related to student poverty need to be addressed. Such issues as school feeding, provision of scholarships to poor children, reduction of school distance from home etc. need to be addressed. Moreover, development partners can play special roles to create capacity at different levels. They can support the training of teachers both at regular and professional development levels. They can work the Ministry of Education to change and improve competences at higher levels. These 
partners can also support schools in school-based professional development of teachers. They can play a vital role in changing the school and classroom environment by providing resources. They can also prepare exchange programs for teachers to share experiences.

\section{REFERENCES}

Abd-El-Khalick, F., H. Boyle, and D. Pier.( 2006). Educational Quality in Islamic Schools, Report No. 1: Nigeria. Washington, DC: USAID Education Quality Improvement Project 1.

Alexander, R. (2000). Culture and Pedagogy. Malden, MA: Blackwell Publishing.

American Institute for Research/AIR/ and Academy for Educational Development/AED/ (2006). Challenges to Promoting Active-Learning, Student-Centered Pedagogies. USAID.

Astin, A. (1993). What Matters in College? Four Critical Years Revisited. San Fransisco, CA: JosseyBass.

Asgedom, A., D. Desta, D. Dufera., W. Leka, with E. Leu, K. Barrow and A. (2006). Ethiopia Pilot Study on Teacher Professional Development. Quality in Education, Teaching, and Learning: Perceptions and Practice. Washington, DC: USAID/Education Quality Improvement Project 1

Barrow, K., B. Helen, M. Ginsburg, E. Leu, P. Daniel, A. Price-Rom and R. Valeria. (2006). CrossNational Synthesis of Educational Quality Report No. 2: Professional Development and Teachers' Conceptions of Educational Quality. Washington, DC: USAID/Education Quality Improvement Project 1.

Bell, B.S. and S.W.J.Kozlowiski (2007). "Active Learning: Effects of Core Training Design Elements on Self-Regulatory Processes, Learning and Adaptability". Journal of Applied Psychology, Vol.92, No.1, pp.107-127 Applied Psychology, Vol.92, No.1, pp.107-127.

Bernstein, B. (1971). "A Socio-Linguistic Approach to Socialization: With Some Reference to Educability." In Class, Codes and Control, Volume I: Theoretical Studies towards a Sociology of Language, pp. 143-69. London: Routledge and Kegan Paul.

Bonwell,C.C. and J.A. Eison (1991). "Active learning. Creating Excitement in the Classroom. ASHEERIC Higher Education Report N0.1. Washington,D.C.: George Washington University.

Bransford, J., A.Brown, and R.Cocking, (1999). How People Learn: Body, Maind, Expereince and School. Washington, DC: National Academy Press.

Braxton,J.M.,Milen, J.F. and Sullivan, A.S. (2000). "The Influence of Active Learning on the College Student Departure Process." The Journal of Higher Education, Vol.71. No.5.

Burrell,G. and Morgan,G. (1996).Organizational Paradigms and Organization Analysis. Hamphire/ England: Ashgate

Darling-Hammond, L., and J. Bransford, (Eds.) (2005). Preparing Teachers for a Changing World: What Teachers Should Learn to Be Able to Do. San Francisco: Jossey-Bass.

Desta, D., et al. (2009). "Enhancing Active Learning through Self- and- Peer Reflections: The Case of Selected schools in Ethiopia." Journal of International Cooperation in Education, Vol.12 No.1, pp.71 $\sim 87$

Duferaa, D.S. (2006). Tension between Traditional and Modern Teaching Approaches in Ethiopian Primary Schools. Journal of International Cooperation in Education, Vol.9, No.1, pp.123 140

Eggleston, J. (1977). The Sociology of the School Curriculum. London: Routledge and Kegan Paul.

Farell, 2006). "Active Learning: Theories and Research". Online Journal/ The Lookenstein Center For Jewish Education. http://www.lookstein.org/online_ journal.php/id=260 Federal Democratic Government of Ethiopia (1994).Education Sector Strategy. Addis Ababa:EMPDA

Ford, J.K. and K. Kraiger (1995)." The application of Cognitive constructs and principles to the instructional systems model of training: Implications for needs assessment,design, and transfer". International Review of Industrial and Organizational Psychology. Vol. 10. pp.1-48.

Frese, M., F.Brodbeck, T.Heinbokel, C. Mosser, E.Schleiffenbaum, P.Thiemann (1991). "Errors in Training Computer Skills: On positive function of errors". Human-Computer Interaction. Vol.6, pp.77-93.

Gallagher, S. (1997). "Problem Based Learning: where did it comes from, what does it do and where it is going?" Journal of Education of the Gifted. Vol.20. No.4,pp.332-362. 
Hake,R. (1998). "Interactive Engagement vs. Traditional Methods: A six - Thousand - Student Survey of Mechanics Test Data for Introductory Physics Courses", American Journal of Physics. Vol.66, N0.1, pp.64.

Heinich, R., M.Moldenda, J.D.Russel and S.E. Samaldino (1996). Instrucional Media and Technologies for Learning. Printice-Hall Inc.:New Jersy.

Hopkins, D., ( 2001). School Improvement for Real. London and New York: Routledge Falmer.

Ivancic, K., and B. Hesketh (1995). "Making the best errors during Training".Training Research Journal. Vol. 1. pp. 103-125.

Johnson, D., R.Johnson and K. Smith (1998). "Cooperative Learning Returning to College: What Evidence Is There that it Works?" Change, Vol.30, No.4, pp.26-35.

Kocsev, M., Hansen,N., Hollow,D. and Pischetola, M. (2010). Innovative Learning in Ethiopia. (unpublished paper).

Kolb,D.A. (1984). Experiential Learning: experience as the Source of Learning and Development. Englewood Cliffs, NJ: Prentice Hall.

Laws,P.,D.Sokoloff, and R.Thornton (1999). "Promoting Active Learning Using the Results of Physics Education Research". Uniservice Science News, Vol.13.

Leu, E. (2005). The Role of Teachers, Schools, and Communities in Quality. Education: A Review of the Literature. Washington, DC: AED, Global Education Center Leu, E. and A. Price-Rom, (2006). Quality of Education and Teacher Learning: A Review of the Literature. Washington, DC: USAID Educational Quality Improvement Project 1.

Martensen, D., H. Ericksson, and H.Ingleman-Sundberg (1985). "Medical Chemistry: Evaluation of Active and Problem Oriented Teaching Methods". Medical Education. Vol.19.pp.34

McNab,C. (1989).Language Policy and Language Practice: Dilemmas of Implementation in Ethiopian Education. Stockholm, Gotab.

Melese, W, Tadesse, T. and Asefa,W.(2009). "The Practice of Learner-Centered Method in Upper Primary Schools of Ethiopia." Ethiopian Journal of Education and Science, Vol.4, No.2, pp 2744.

MOE (2007). Ethiopian Third National Learning Assessment Grade 4 and 8 Students. Addis Ababa: MOE/BES.

Morgan, C.T., R.A. King, J.R. Weisz and J. Schopler(1999). Introduction to Psychology. New Delhi: Tata McGraw-Hill.

Negash,T. (1990). The Crises of Ethiopian Education: Some Implications for. Nation Building Uppsala: Reprocentralen HSC

Negash,T. (2006).Education in Ethiopia: from Crises to the Brink of Collapse. Discussion Paper 33 .Uppsala:Nordic Africa Institute.

Norman, G. and H.Schmidt (2000). "Effectiveness of Problem Based Curricula: Theory, Practice and Paper Darts". Medical Education. Vol.34, pp.721-728.

Prince, (2004). Does Active Learning Work? A Review of the Research. Journal of Engineering Education, 93 (3). 223-231.

Redish, E., J. Saul, and R. Steinburg (1999). "On the Effectiveness of Acive-Engagement MicroComputer Based Laboratories". American Journal of Physics. Vol.65,No.1.pp.45.

Revans, R.W. (1982). The Origins and Growth of Action Learning. Bromley, UK: Chartwell-Bratt.

Rocha, V. (2006). Pilot Study on a Transitional Education Program for Out-of-School Girls in India. Washington, DC: USAID Education Quality Improvement Project 1.

Ruhl,K., C.Hughes, and P. Schloss (1987). Using the Pose Procedure to Enhance Lecture Recall. Teacher Education and Special Education, Vol, 10.pp.14-18.

Salas, E., and J.A. Cannon-Bowers (2001). “The Science of Training: A Decade of Progress".Annual Review of Psychology, Vol.52. pp 471-499.

Schwarz, D.L., and J.D.Bransford (1998). "A Time for Telling”. Cognition and Instruction. Vol.16, PP.475-522.

Silberman, M. (1996). Active Learning: 101 Strategies to teach any subject. London: Allyn and Bacon. 
Siraj-Blatchford,I. O., Matthews, and O., Martin (2002). "Supporting Child - Centred. Teaching under Universal Primary Education in Kampala, Uganda." In Stephen Anderson (ed.) Improving Schools through Teacher Development: Case Studies of the Aga Khan Foundation Projects in East Africa, pp. 117-36. Lisse, Netherlands: Swets \& Zeitlinger.

Springer, L., M. Stanne and S. Donnovan (1999). "Effects of Small Group Learning on Undergraduates in Science, Mathematics, Engineering and Technology:AMeta-Analysis". Review of Educational Research. Vol. 69, No.1. pp.21-52.

Stockcard, J., and M.Mayberry (1996). Effective Educational Enviroments. California: Corwin Press, Inc.

Transitional Government of Ethiopia (1994). Education and Training Policy. Addis Ababa: EMPDA.

Van Graan, M. and E. Leu (2006). "Namibia Pilot Study of Teacher Professional Development". Quality in Education, Teaching, and Learning: Perspectives and Practice. Washington, DC: USAID Education Quality Improvement Project 1.

Vernon , D, and R. Blake (1993). "Does Problem-Based Learning Work? A Meta-Analysis of Research". Academic Medcicine.Vol.68, No.7.

Vygotsky, L.S. (1978). Mind and Society: The development of higher mental processes. Cambridge, MA: Harvard University Press.

UNESCO (2004). EFA Global Monitoring Report 2005: Education for All-The Quality Imperative. Paris: UNESCO.

\section{AUTHOR'S BIOGRAPHY}

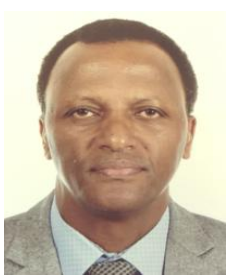

Teshome Nekatibeb Begna, is a $\mathrm{PhD}$ in International and Comparative Education from Stockholm University, Sweden. He was involved in Post-Doctoral Research in the University of Kassel, Center for Higher Education Research (UNCHER) in Germany. He served at Addis Ababa University, Ethiopia as Associate Professor and founded the Center for Comparative Education and Policy Studies. Dr. Nekatibeb has also worked in International Development for many years. He was a Technical Advisor for Monitoring, Evaluation and Policy Analysis for Academy for Educational

Development in Ethiopia's BESO project. He also served as a Monitoring and Evaluation Senior Specialist for RTI- International in Jordan and as Senior Education Advisor for Creative Associates International in Afghanistan. Dr. Nekatibeb has served as a consultant for several international institutions including the World Bank, UNICEF, UNESCO, NORAD, Young Lives and KPMG both inside and outside Ethiopia for several years. 